Journal of Engineering and Applied Sciences 14 (Special Issue 8): 10278-10284, 2019

ISSN: 1816-949X

(C) Medwell Journals, 2019

\title{
Preparation and Characterization of Yttria Stabilized Zirconia Blocks from Waste Dental Implant by Computer-Aided Manufacturing (CAM)
}

\author{
Iman Jabber Abed and Noor Hashim Abed Al-Manaf \\ Department of Materials Engineering, University of Kufa, Najaf, Iraq
}

\begin{abstract}
The preparation of zirconia waste powder by sieving the powder, milling and after that characterization of the zirconia recycled zirconia powder by the particle size analyses, XRD and SEM. Then preparation of the pre sintered Yttria-Tetragonal Polycrystall (3Y-TZP) blocks from the dental implant waste by different uniaxial pressures $(75,100$ and $145 \mathrm{MPa})$ and different presintering temperature $\left(950,1100^{\circ} \mathrm{C}\right)$. Then characterization of the Yttria-Tetragonal Polycrystall (3Y-TZP) blocks by XRD, SEM and EDS. The results showed (XRD) produce tetragonal phase with small amount of monoclinic phase of zirconia waste powder. While the results of the pre sintered Zirconia (3Y-TZP) showed disappeared the monoclinic phase and remained only the tetragonal phase and therefore it is possible to reuse the waste dental implant zirconia powder from used blocks and can be milling by the $\mathrm{CAD} / \mathrm{CAM}$ and the suitable presintering temperature to reuse the powder only $950^{\circ} \mathrm{C}$ due to the similar properties to the commercial blocks.
\end{abstract}

Key words: $\mathrm{CAD} / \mathrm{CAM}$, recycled, zirconia, compaction, sintering, milling

\section{INTRODUCTION}

The mostly utilize for biomedical application are ceramic materials due to mechanical and biological characterize because of beneficial properties such as strength and biocompatibility (Pittayachawan, 2009). Ceramics are mostly utilized as restorative materials, the widely utilized ceramic material in dentistry for manufacture substructures is Yttria Partially stabilized Tetragonal Zirconia (Y-TZP) because of its beneficial optical and mechanical properties (Alsadon et al., 2017).

The modern developed biomaterials are bioceramic, it's utilized for bio application such as bone and hip transplants. Bioceramic are profitable in dentistry as a result of idleness in the body liquids extensive compressive quality and stylishly satisfying look. The development of industrial technology and biomaterials science, benefit in ceramics for dental use has been restore, especially, the Yttrium-stabilized Tetragonal Polycrystalline Zirconia (Y-TZP) show enhance mechanical characterize make them proper substrates for the manufacture of dental insert (Kaplan et al., 2016).

Dental ceramics can be description inorganic composite with non-metallic it is compound of first or much and metal or semi metal and oxygen compound such as silicon, titanium, zirconium, aluminum and magnesium it is organize according to their melting temperature, chemical structure, application, processing way and base material (Pittayachawan, 2009). Computer aided designed/computer aided manufacture technique which produce to dentistry and move toward becoming to a special manufacturing choice for circuitous dental rebuilding efforts. $\mathrm{CAD} / \mathrm{CAM}$ was initially produce to manufacturing ceramic blocks were fully sintered and it is utilized to machining presented blocks ceramics which undergo to fully sintered subsequently (Denry and Holloway, 2010). This research aims to recycling waste of $\mathrm{ZrO}_{2}$ ( $\left.3 \mathrm{~mol} \% \mathrm{Y}-\mathrm{TZP}\right)$ from machining centers and manufacturing crowns by computer aided design and manufacturing techniques.

\section{MATERIALS AND METHODS}

Experimental part: In this study it was used waste powder of the machined CAD/CAM discs of zirconia $\left(3 \mathrm{Y}-\mathrm{ZrO}_{2}\right)$ from Vita Zahnfabrik Scckingen Germany zirconia.

Sieving and milling the starting material: The starting material produced from the machining was in the form disk, so that, milling by used windmill house and then sieving by used mesh $200(0.0125 \mathrm{~mm})$ and then milling by container ball grinder (SMF, Disk, Top, planter ball miller). The milling time was two and half hours and speed of milling $450 \mathrm{rpm}$.

Characterization of recycled powder: The prepared powder was inspected by XRD, particle size analysis and Scanning Electron Microscopic (SEM).

Particle size analysis: After the powder milled by planetary ball mill. The particle size and particle size distribution was measured by using laser particle size analysis (Bettersize 2000 laser particle size analyzer). 

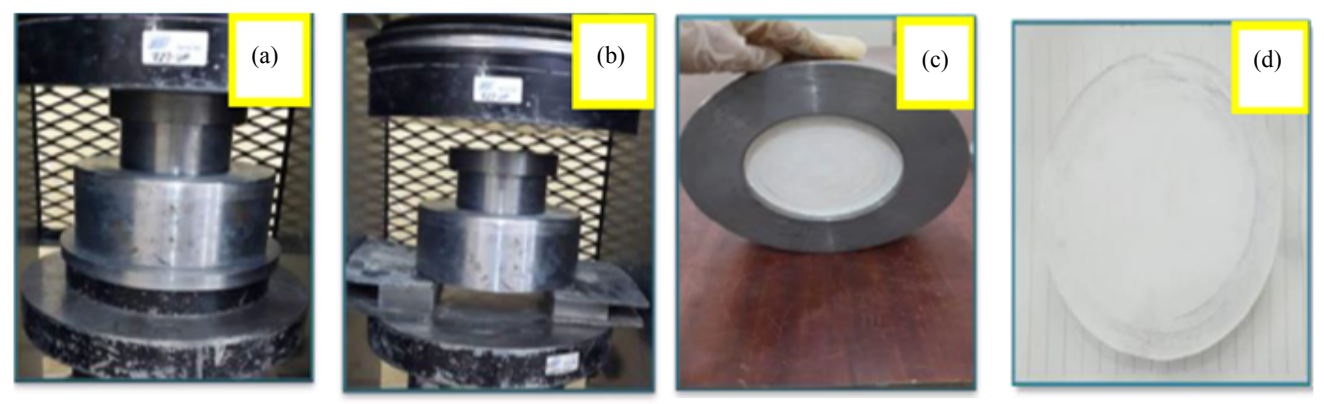

Fig. 1: Illustration of the steps in compaction process: (a) The mold filling by powder, (b) The powder compaction in order to take size and shape recording, (c) Remove the green body from mold and (d) The green body

X-Ray diffraction pattern: In order to study the phases existed in the prepared 3Y-TZP powder, the powder was qualitatively described by utilizing (XRD-6000 SHIMADZU X-ray diffract meter, Japan). XRD examination is one of the most essential tools to identify the phases in powder specimens.

Scanning electron microscopic: Scanning Electron Microscope (SEM) is a helpful instrument to study the morphology of the phases within the sample by producing a magnified images with magnifications power ranged from 20 up to 50,000 (Cossu et al., 2018). The prepared powder was scanned by using scanning electron microscopy (inspect S50 SEM, Japan) in order to characterization the particles shapes, distribution of particles and the particle micro structure.

\section{Preparation of sample}

Compaction of the powder: The powder mixed with the binder Poly Vinyl Alcohol (PVA) and then pressing at three different compaction pressure $(75,100$ and $145 \mathrm{MPa}$ ). The holding time used $60 \mathrm{sec}$ the weight and diameter ratio of the mold used for the used compaction pressure was $7.5 \mathrm{~g}, 20 \mathrm{~mm}$, respectively weighted in four digits balance (Denver instrument, TP-3031, Germany). The mold used for the machining the of the waste zirconia blocks by the computer aided designed/computer aided manufacture as shown in Fig. 1 has the diameter 110 and the weight of the powder used $300 \mathrm{gm}$ utilizing (CT340 Automatic $2000 \mathrm{kN}$ cylinder pressure device).The force can be estimated according to Eq. 1. which used in the compaction:

$$
\mathrm{F}=\sigma \times \mathrm{A}
$$

Where:

$\mathrm{F}$ : Force applied $(\mathrm{kN})$

$\sigma$ : The stress (MPa)

A : The area of the sample perpendicular to the applied load (a)

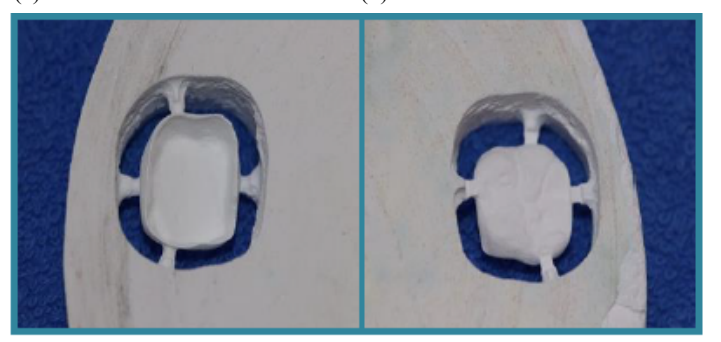

Fig. 2(a, b): Illustration of the machined crown from waste dental implant blocks

Partial sintering: After the compaction the powder in different sample and before the pre sintering the green body dried in $120^{\circ} \mathrm{C}$ for $5 \mathrm{~h}$ in dried oven at laboratories of Materials Engineering Department/Faculty of Engineering/University of Kufa, firstly heating to $600^{\circ} \mathrm{C}$ in order to remove any binder with slow heating rate $5^{\circ} \mathrm{C} \mathrm{min}{ }^{-1}$ and then sintering to 950 and $1100^{\circ} \mathrm{C}$ with holding time $2 \mathrm{~h}$ and heating rate $6^{\circ} \mathrm{C} \mathrm{min}^{-1}$.

Milling by CAD/CAM and full sintering: Before milling the blocks by the computer aided designed/computer aided manufacture the sample is pre sintering at $950-1100^{\circ} \mathrm{C}$, the holding time $2 \mathrm{~h}$ and the heating rate $10^{\circ} \mathrm{C} \mathrm{min}{ }^{-1}$. When the surface of the blocks is soft the milling by $\mathrm{CAD} / \mathrm{CAM}$ become very easy. The pre sintering blocks is milled dry by the $\mathrm{CAD} / \mathrm{CAM}$ as shown in Fig. 2 after milling the pre sintered crown is fully sintering in a sintering furnace (Zirkonzahn). Then the crowns are fully sintering at $1500^{\circ} \mathrm{C}$ as shown in Fig. 3, the holding time $2 \mathrm{~h}$ and the heating rate $10^{\circ} \mathrm{C} \mathrm{min}{ }^{-1}$ for all specimens used in order to prevent the stress-prompted change from the phase of tetragonal to the phase of monoclinic and take the surface free from the phase of monoclinic (Ebert et al., 2009).

Characterization of zirconia block: To identify the phases and morphology of the pre sintered and full sintered 3Y-TZP samples SEM and X-ray are used. 


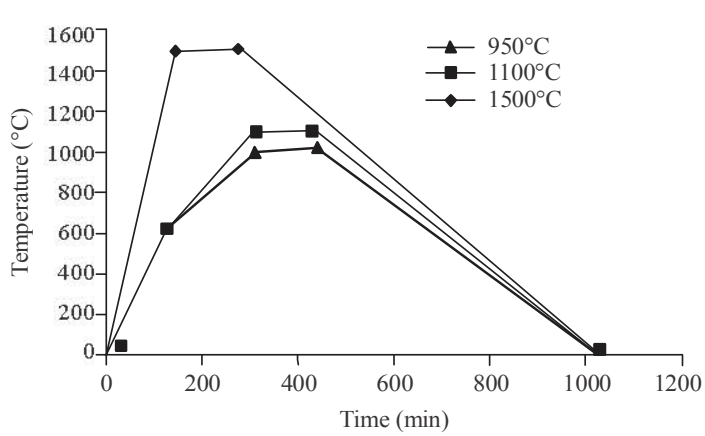

Fig. 3: Illustration of heating rate of the partial and full sintering

The $\mathrm{X}$-ray diffraction pattern: $\mathrm{XRD}$ is the methods to investigate the phase composition and to study the structure of the material. X-ray diffraction analysis was carried out for the several compositions to study the phases present. Copper radiation with wavelength of $1.5406 \mathrm{~A}^{\circ}$ was used for the study and values were recorded in continuous scanning mode (Ngombane, 2018).

Scanning Electron Microscopic (SEM): SEM is the a technique which utilized to get the image of the surface of specimen has great resolve. In this technique the surface of the specimen hit by the dissimilar type of electron to examination because of electron specimen communication and utilized high energy to examination after that the signs are expected and analyzed on a choosy region of the surface of the specimen it is generated the image have two dimension in added to the image of the specimen. Scanning electron microscopy can be utilized to analyses of choosy sit from the specimen by utilized the Energy Dispersive Spectroscopy (EDS) it is appropriate for define the element found in the specimen (Ding, 2016). All the specimen grinding by the silicon carbide paper from $120-2000 \mu \mathrm{m}$ and after that polishing by the alumina powder the particle size $5 \mu \mathrm{m}$. After that specimens were thermally etched in 1300 for $1 \mathrm{~h}$ by using box furnace (P300, Naber therm, made in Germany)

\section{RESULTS AND DISCUSSION}

Figure 4 displays the particle size analysis of the recycled Yttria-Tetragonal Zirconia Polycrystal (3Y-TZP) dental implant after $4 \mathrm{~h}$ milling. As can be seen from the chart, the median size of the particles (D 50) was $0.346 \mu \mathrm{m}$. Figure 5 displays the results of X-ray diffraction pattern of recycled Yttria-Tetragonal Zirconia Polycrystal (3Y-TZP) dental implant powder, the results indicated tetragonal zirconia phase with small amount of monoclinic phase in $2 \theta=28.11$ and $31.35^{\circ}$. Micro structural investigations which include study micro

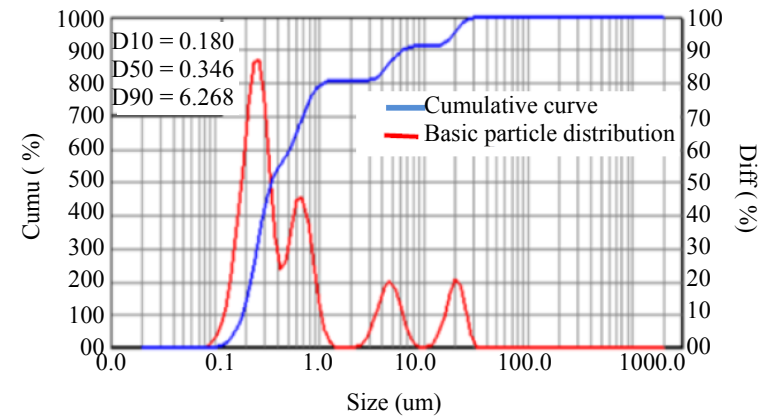

Fig. 4: The particle size analysis of recycled Yttria-Tetragonal Zirconia Polycrystal (3Y-TZP) denta implant after $4 \mathrm{~h}$ milling

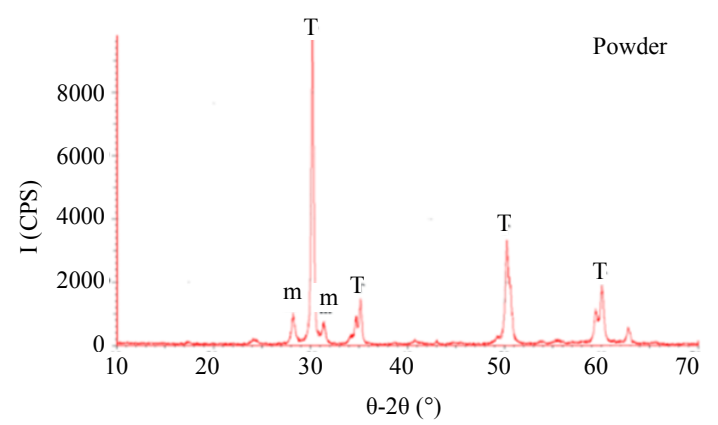

Fig. 5: X-ray diffraction pattern of recycled Yttria-Ttetragonal Zirconia Polycrystal (3Y-TZP) dental implant powder after $4 \mathrm{~h}$ milling

structure recycled powder of Yttria-Tetragonal Zirconia Polycrystal (3Y-TZP) dental implant by using scanning electron scanning electron microscopy linked with an energy dispersive spectrometry attachment. Figure 6 shows the morphology of recycled Yttria-Tetragonal Zirconia Polycrystal (3Y-TZP) dental implant powder at different magnification. It is found the result of the scanning electron microscopic of particles. These particles exhibit considerable irregularities and some agglomeration this result it is agree with researcher (de Assis et al., 2014). Energy Dispersive Spectrometry (EDS) micro analysis in the scanning electron microscope was used to identify the chemical composition of phases present in the recycled Yttria-Tetragonal Zirconia Polycrystal (3Y-TZP) powder as shown in Fig. 7. The peaks are labeled with a red square for the zirconium, pink square for the yttria and with a green square for the oxygen.

Figure 8 displays the $\mathrm{X}$-ray diffraction pattern after the pre sintered and full sintered of recycled Yttria-Tetragonal Zirconia Polycrystal (3Y-TZP) at different sintering temperature. It is found that the monoclinic phase is displeased and has in has been completely changed to the tetragonal phase when sintering at the temperature $\left(950,1100\right.$ and $\left.1500^{\circ} \mathrm{C}\right)$. This results it is agree with many 
(a)

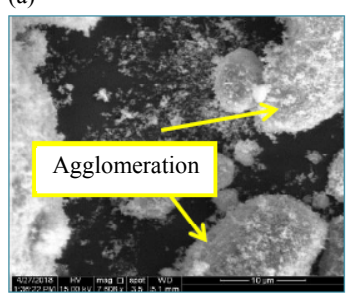

(b)

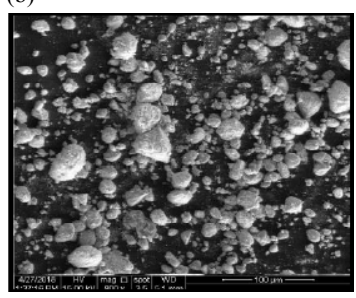

Fig. 6(a, b): Scanning electron microscopy images showing morphology of recycled YttriaTetragonal Zirconia Polycrystal (3Y-TZP) powder at different magnification power

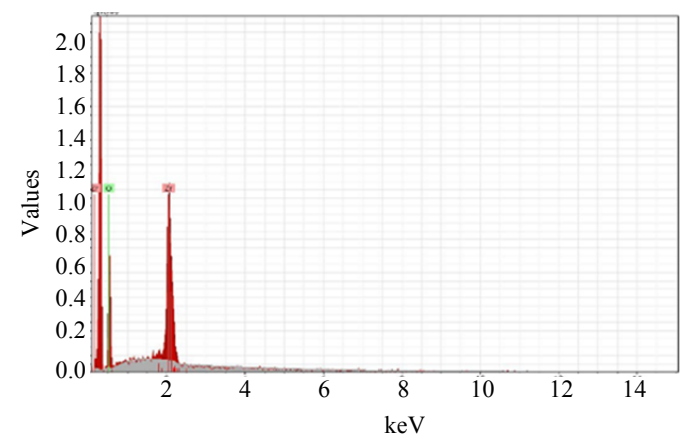

Fig. 7: The energy dispersive spectroscopy of recycled Yttria-Tetragonal Zirconia Polycrystal (3Y-TZP) dental implant powder researcher's results (Silva et al., 2017; de Assis et al., 2014; Gouveia et al., 2017). Figure 9a-c shows the SEM of the pre sintered commercial Yttria-Tetragonal Zirconia Polycrystal (3Y-TZP) at different magnification power it can be observed the surface of the original block is flat, smooth, fine scratches with very fines pores Fig. 9. Energy dispersive X-ray spectroscopy has been done after SEM for the selected area of the pre sintered commercial sample. The results has been shown in Fig. 10 for the commercial block.

The peaks are labeled with a green square for the zirconium, yellow square for the aluminum, violet square for the yttria and with a red square for the oxygen. The quantitative analyses of the element in the commercial blocks are labeled in Table 1. Figure 11a-c shows the image of prepared samples from recycled Yttria-Tetragonal Zirconia Polycrystal (3Y-TZP) dental implant after the pre sintered at $950^{\circ} \mathrm{C}$ in different magnification power it is found that the micro structure of the sample involved basic and collected particles together, the collected particles were basic particles powerfully joined together. The collected particle displayed in Fig. 11 microcracks and pores were observed.

Figure 12 shows the energy dispersive spectroscopy of recycled Yttria-Tetragonal Zirconia Polycrystal (3Y-TZP) pre sintered block at $950^{\circ} \mathrm{C}$. The quantitative analyses of the element in the pre sintered blocks of the yttria-tetragonal polycrystalline can be shown in Table 2 .

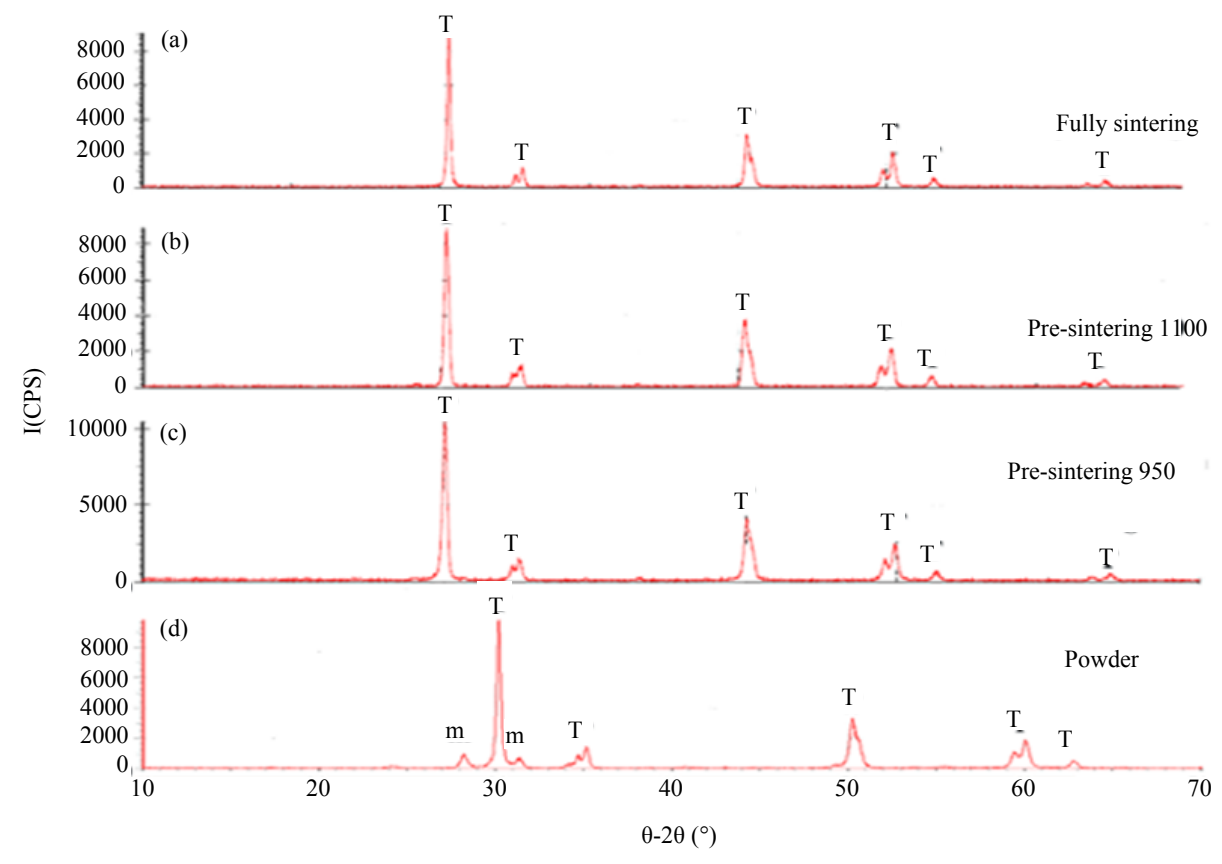

Fig. 8: X-ray diffraction pattern of recycled Yttria-Tetragonal Zirconia Polycrystal (3Y-TZP) blocks after pre sintering and fully sintering (a) Full sintering at $1500^{\circ} \mathrm{C}$, (b) Pre sintering at $1100^{\circ} \mathrm{C}$, (c) Pre sintering at $950^{\circ} \mathrm{C}$ and (d) Recycled powder 

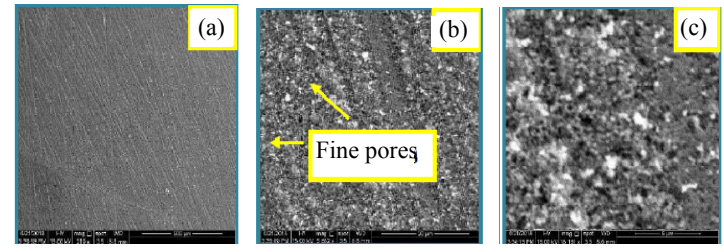

Fig. 9 (a-c): Scanning electron microscopy images of pre sintered commercial Yttria-Tetragonal Zirconia Polycrystal (3Y-TZP) in different magnification power

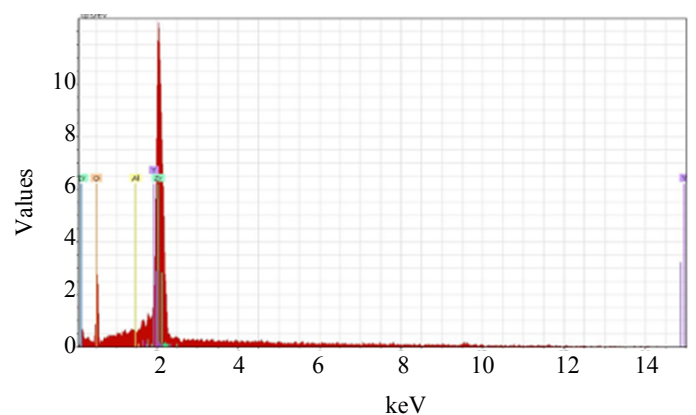

Fig. 10: The energy dispersive X-ray spectroscopy of the of commercial Yttria-Tetragonal Zirconia Polycrystal (3Y-TZP) block

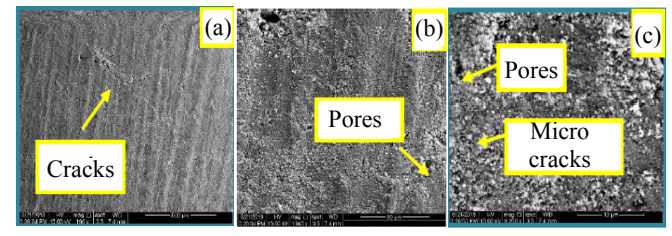

Fig. 11(a-c): Scanning electron microscopy images of pre sintered recycled Yttria-Tetragonal Zirconia Polycrystal (3Y-TZP) at $950^{\circ} \mathrm{C}$ in different magnification power

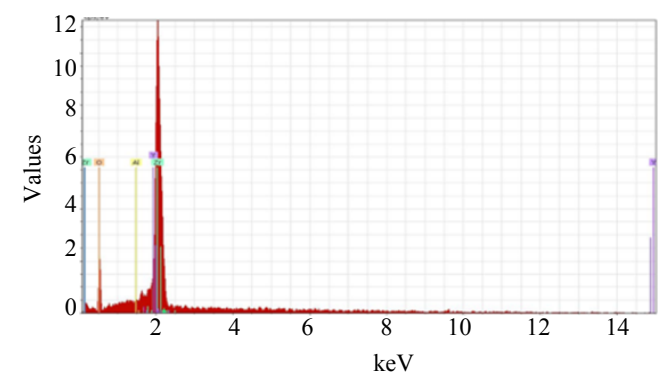

Fig. 12: The energy dispersive spectroscopy of the recycled Yttria-Tetragonal Zirconia Polycrystal (3Y-TZP) pre sintered blocks at $950^{\circ} \mathrm{C}$

The peaks are labeled with a green square for the zirconium, yellow square for the aluminum, violet square

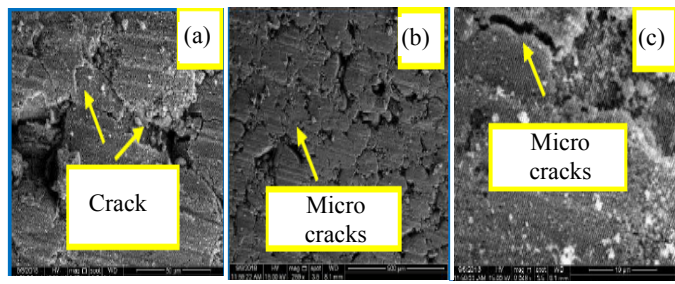

Fig. 13(a-c): Scanning electron microscopy images of pre sintered recycled Yttria-Tetragonal Zirconia Polycrystal (3Y-TZP) at $1100^{\circ} \mathrm{Cat}$ different magnification power

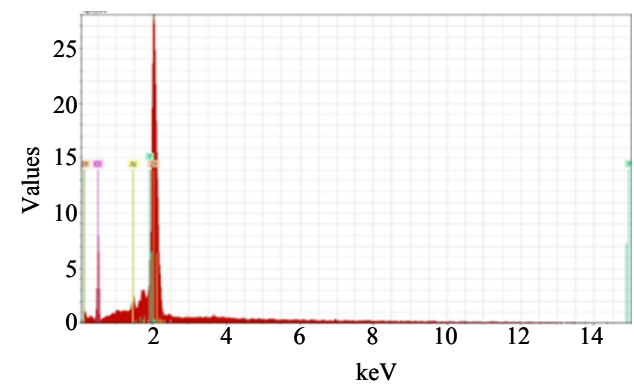

Fig. 14: The energy dispersive spectroscopy of the recycled Yttria-Tetragonal Zirconia Polycrystal (3Y-TZP) pre sintered blocks at $1100^{\circ} \mathrm{C}$

Table 1: The quantitative analyses of the of commercial Yttria-Tetragonal Zirconia Polycrystal (3Y-TZP) block

\begin{tabular}{lr}
\hline Element & wt.\% \\
\hline Zirconium & 66.67 \\
Oxygen & 20.42 \\
Yttria & 12.75 \\
Aluminum & 0.16 \\
\hline
\end{tabular}

Table 2: The quantitative analyses of the Recycled Yttria-Tetragonal

\begin{tabular}{lc}
\multicolumn{2}{c}{ Zirconia Polycrystal (3Y-TZP) pre sintered blocks at $950^{\circ} \mathrm{C}$} \\
\hline Element & wt. $\%$ \\
\hline Zirconium & 66.85 \\
Oxygen & 21.30 \\
Yttria & 11.58 \\
Aluminum & 0.0 \\
\hline
\end{tabular}

for the yttria and with a red square for the oxygen. Figure 13 shows the image of prepared samples from recycled Yttria-tetragonal Zirconia Polycrystal (3Y-TZP) dental implant after the pre sintered at $1100^{\circ} \mathrm{C}$ in different magnification power. It is found the micro structure of the sample consisted of basic and collected particle and it is found the collected particles were basic particles more powerfully joined together than the particle presintering in the temperature $1100^{\circ} \mathrm{C}$ in Fig. 13a-c micro cracks and pores were observed.

Figure 14 shows the energy dispersive spectroscopy of recycled Yttria-Tetragonal Zirconia Polycrystal (3Y-TZP) pre sintered block at $1100^{\circ} \mathrm{C}$. The quantitative analyses of the element in the pre sintered blocks of the yttria-tetragonal polycrystalline can be shown in Table 3 . 
Table 3: The quantitative analyses of the recycled Yttria-Tetragonal Zirconia Polycrystal (3Y-TZP) pre sintered block at $1100^{\circ} \mathrm{C}$

\begin{tabular}{lr}
\hline Element & wt.\% \\
\hline Zirconium & 60.95 \\
Oxygen & 24.83 \\
Yttria & 13.34 \\
Aluminum & 0.88 \\
\hline
\end{tabular}

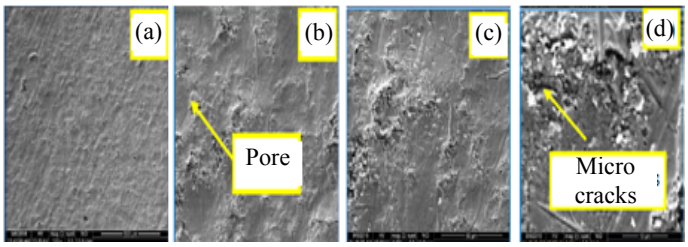

Fig. 15(a-d): Scanning electron microscopy image for full sintered at $1500^{\circ} \mathrm{C}$ of commercial Yttria-Tetragonal Zirconia Polycrystal (3Y-TZP) sample

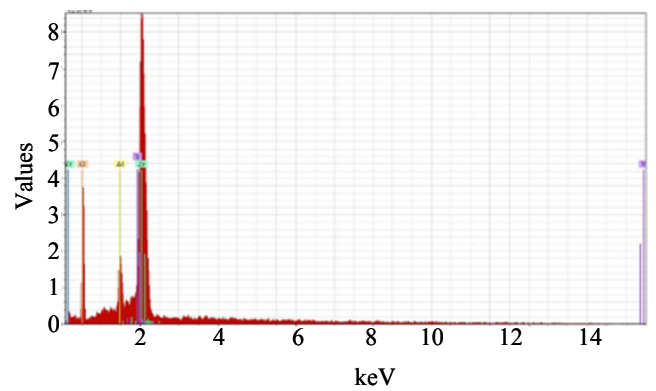

Fig. 16: The energy dispersive spectroscopy for the commercial block of Yttria-Tetragonal Zirconia Polycrystal (3Y-TZP) after the full sintering at $1500^{\circ} \mathrm{C}$

The peaks are labeled with a green square for the zirconium, yellow square for the aluminum, violet square for the yttria and with a red square for the oxygen.

Figure 15 shows the SEM of the commercial Yttria-Tetragonal Zirconia Polycrystal (3Y-TZP) after the fully sintering at $1500^{\circ} \mathrm{C}$ at different magnification power it can be seen the surface of the original blocks smooth when compared with the waste zirconia blocks and consisted of fine pores and less microcracks and as we can see that it's particle were quite evenly distributed as shown in Fig. 15a-d. Figure 16 shows the result of the energy dispersive spectroscopy after the full sintered blocks commercial Yttria-Tetragonal Zirconia Polycrystal (3Y-TZP). The quantitative analyses of the element in the full sintered blocks of the yttria-tetragonal polycrystalline can be shown in Table 4. The peaks are labeled with a green square for the zirconium, yellow square for the aluminum, violet square for the yttria and with a red square for the oxygen.

Figure 17 shows the scanning electron microscopy images of recycled Yttria-Tetragonal Zirconia Polycrystal
Table 4: The quantitative analyses of the full sintering commercial blocks sintering at $1500^{\circ} \mathrm{C}$

\begin{tabular}{lr}
\hline Element & wt.\% \\
\hline Zirconium & 60.95 \\
Oxygen & 23.83 \\
Yttria & 11.81 \\
Aluminum & 3.41 \\
\hline
\end{tabular}

Table 5: The quantitative analyses of the full sintering blocks sintering

\begin{tabular}{|c|c|}
\hline Element & wt.\% \\
\hline Zirconia & 55.27 \\
\hline Oxygen & 30.64 \\
\hline Yttria & 10.58 \\
\hline Aluminum & 3.51 \\
\hline
\end{tabular}
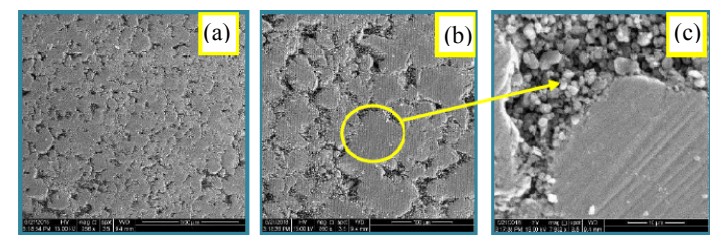

Fig. 17(a-c): Scanning electron microscopy image for full sintered at $1500^{\circ} \mathrm{C}$ of recycled Yttria-Tetragonal Zirconia Polycrystal (3Y-TZP) sample

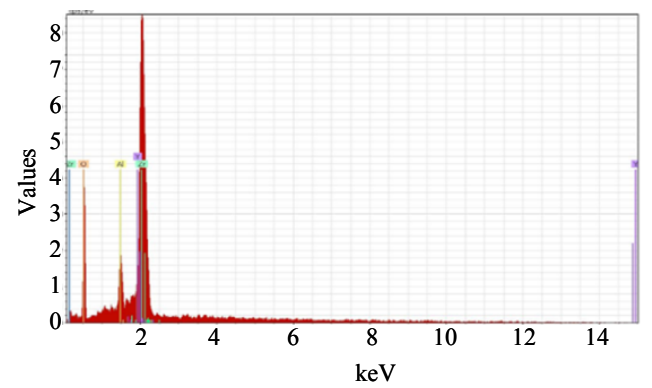

Fig. 18: The energy dispersive spectroscopy for the block of Yttria-Tetragonal Zirconia Polycrystal (3Y-TZP) after the full sintering at $1500^{\circ} \mathrm{C}$

(3Y-TZP) samples when sintering at $1500^{\circ} \mathrm{C}$ in different magnification power, it can be noticed the particle more evenly distributed and we can see the opening between the particle were fewer. At the point when the sintering temperature fluctuates, the shapes and sizes of the grains may likewise change. The grains were fine and extended when sintered at a low temperature (roughly $950^{\circ} \mathrm{C}$ ). By expanding the sintering temperature to $1500^{\circ} \mathrm{C}$, the grains ended up bigger and coarser and pores be less. Figure 18 shows the result of the energy dispersive spectroscopy after the full sintered blocks of Yttria-Tetragonal Zirconia Polycrystal (3Y-TZP). The quantitative analyses of the element in the full sintered blocks of the yttria-tetragonal polycrystalline can be shown in Table 5 . The peaks are labeled with a green square for the zirconium, yellow square for the aluminum, violet square for the yttria and with a red square for the oxygen. 
From the result of the EDX quantitative analyses it is found the waste zirconia dental implant when compared with the commercial block and the powder had a similar components like (zirconium, yttria, aluminum and oxygen). Each key components had their own capacity.

\section{CONCLUSION}

Appearance tetragonal zirconia phase with small amount of monoclinic phase in $2 \theta=28.11$ and $31.35^{\circ}$ in the recycled zirconia dental implant powder and disappear the monoclinic phase and remained only the tetragonal phase in the pre and full sintered samples. It is possible to milling the pre sintered blocks of recycled zirconia dental implant by the $\mathrm{CAD} / \mathrm{CAM}$ and the optimum presintering temperature is $950^{\circ} \mathrm{C}$ of soft machining for the blocks of recycled zirconia of dental implant. It is possible to reuse of the recycled Yttria-Tetragonal Polycrystal (3Y-TZP) blocks by the soft machining computer aided designed/computer aided due to the similar characterization of to the commercial blocks.

\section{ACKNOWLEDGEMENT}

The researchers would like to express their appreciation to the University of $\mathrm{Kufa} /$ College of Engineering/Materials Engineering Department for its support of this research. The researchers would like to thank all the technicians in the laboratories for their valuable help.

\section{REFERENCES}

Alsadon, O., D. Patrick, A. Johnson, S. Pollington and D. Wood, 2017. Fracture resistance of zirconia-composite veneered crowns in comparison with zirconia-porcelain crowns. Dent. Mater. J., 36: $289-295$.
Cossu, C.M.F.A., P. Alves, M.F. Rodrigues, L.C.L. de Assis and R.D.O. Magnago et al., 2018. Development and characterization of $\mathrm{Al} 2 \mathrm{O} 3-\mathrm{ZrO} 2$ Composites Using $\mathrm{ZrO} 2$ (Y2O3)-recycled as raw material. Mater. Sci. Forum, 912: 124-129.

Denry, I. and J.A. Holloway, 2010. Ceramics for dental applications: A review. Mater., 3: 351-368.

Ding, H., 2016. Recycling zirconia dental prostheses waste: A feasibility study. MSc Thesis, The University of Hong Kong, Pok Fu Lam, Hong Kong.

Ebert, J., E. Ozkol, A. Zeichner, K. Uibel and O. Weiss et al., 2009. Direct inkjet printing of dental prostheses made of zirconia. J. Dent. Res., 88: 673-676.

Gouveia, P.F., L.M. Schabbach, J.C.M. Souza, B. Henriques and J.A. Labrincha et al., 2017. New perspectives for recycling dental zirconia waste resulting from $\mathrm{CAD} / \mathrm{CAM}$ manufacturing process. J. Cleaner Prod., 152: 454-463.

Kaplan, M., A. Ozturk and J. Park, 2016. Production and characterization of yttria stabilized zirconia ceramic blocks for dental applications. Proceedings of the 18th International Congress on Metallurgy and Materials Engineers, September 29, 2016, Istanbul, Turkey, pp: 324-327.

Ngombane, Y., 2018. Dental laboratory waste management in respect of reusing and recycling in KwaZulu-Natal. MSc Thesis, Durban University of Technology, Durban, South Africa.

Pittayachawan, P., 2009. Comparative study of physical properties of zirconia based dental ceramics. Ph.D Thesis, University College London, London, England.

Silva, L.B., W. Acchar and V.M. Silva, 2017. Study of the sintering dental ceramic waste from $\mathrm{ZrO} 2-\mathrm{Y} 2 \mathrm{O} 3$ system. Mater. Sci. Forum, 881: 392-397.

de Assis, L.C.L., R.M. de Oliveira, C.A.A. da Silva, A.F. Habibe and G.R.L. Villanova et al., 2014. Reuse of $\mathrm{ZrO} 2$ (Y2O3) arising from making dental implant-characterization of materials. Mater. Sci. Forum, 798: 632-637. 